\title{
FAKTOR DAN PENJADUALAN SHIFT KERJA
}

\author{
Lientje Setyawati Maurits ${ }^{1)}$ dan Imam Djati Widodo ${ }^{2)}$ \\ ${ }^{1)}$ Program Studi IImu Kesehatan Kerja, Fakultas Kedokteran, Universitas Gadjah Mada \\ ${ }^{2)}$ Program Studi Teknik Industri, Fakultas Teknologi Industri, Universitas Islam Indonesia
}

\begin{abstract}
Work shift has negative effect in physical and mental health, work performance and job accident. Disturbance of circadian rhythms is indicated as source of the problems. This article explores some researches related to the impacts of work shift and establishes basic principles of work shift scheduling that considers human need and limitation.
\end{abstract}

Keywords: work shift, circadian rhythms, accident, fatique.

\section{PENDAHULUAN}

Keselamatan dan kesehatan kerja merupakan suatu masalah penting dalam setiap proses operasional, baik di sektor tradisional maupun moderen (Silalahi \& Silalahi, 1991). Menurut ILO (2003), setiap hari rata-rata 6000 orang meninggal akibat sakit dan kecelakaan kerja atau 2,2 juta orang per tahun. Sebanyak 350.000 orang per tahun di antaranya meninggal akibat kecelakaan kerja. Kecelakaan kerja juga berakibat pada biaya; 1000 miliar USD atau 20 kali dana bantuan umum yang diberikan ke negara berkembang. Biro Statistik Buruh (Bureau of Labour Statistics) Amerika melaporkan terdapat 5703 kecelakaan fatal atau 3,9 per 100.000 pekerja di tahun 2006 (Industrial Engineer, 2007).

Berdasarkan data ILO tahun 2003, angka keselamatan kerja Indonesia masih sangat buruk, yaitu berada pada peringkat 26 dari 27 negara yang diamati. Pada tahun tersebut, terdapat 51523 kasus kecelakaan kerja yang terdiri dari 45234 kasus cidera kecil, 1049 kasus kematian, 317 kasus catat total dan 5400 cacat sebagian (Suardi, 2005).

Secara umum, terdapat dua golongan penyebab kecelakaan yaitu (1) tindakan/ perbuatan manusia yang tidak memenuhi keselamatan (unsafe human acts) dan (2) keadaan lingkungan yang tidak aman (unsafe condition). Dari beberapa penelitian yang telah dilakukan, faktor manusia menempati posisi yang sangat penting terhadap terjadinya kecelakaan kerja yaitu antara $80-85 \%$ (Suma'mur, 1993).
Salah satu faktor penyebab utama kecelakaan kerja yang disebabkan oleh manusia adalah stress dan kelelahan (fatique). Kelelahan kerja memberi kontribusi 50\% terhadap terjadinya kecelakaan kerja (Setyawati, 2007). Kelelahan bisa disebabkan oleh sebab fisik ataupun tekanan mental. Salah satu penyebab fatique adalah ganguan tidur (sleep distruption) yang antara lain dapat dipengaruhi oleh kekurangan waktu tidur dan ganguan pada circadian rhythms akibat jet lag atau shift kerja (Wicken, et al, 2004). Sharpe (2007) menyatakan bahwa pekerja pada shift malam memiliki resiko $28 \%$ lebih tinggi mengalami cidera atau kecelakaan. Dari beberapa catatan kecelakaan kerja yang terjadi, gangguan tidur dan kelelahan menjadi dua faktor yang paling penting dari kesalahan manusia. Enam puluh persen kecelakaan di Angkatan Udara (AS) disebabkan oleh kelelahan (Palmer et al, 1996). Empat kecelakaan terbesar pusat listrik tenaga nuklir disebabkan oleh faktor manusia pada waktu permulaan shift pagi. Bahkan diperkirakan 200.000 kecelakaan mobil (di AS) per tahun juga disebabkan oleh kelelahan dan ganguan tidur (Harrison \& Horne, 2000).

Kecelakaan dan kesehatan kerja selalu akan berhubungan dengan kelelahan, shift dan waktu kerja. Beberapa penelitian berusaha menerangkan aspek-aspek dari shift dan waktu kerja. Shift dan kerja malam hari adalah kondisi yang dapat menghambat kemampuan adapatasi pekerja baik dari aspek biologis maupun sosial. Shift kerja malam berpengaruh (1) negatif terhadap kesehatan fisik, mental 
dan sosial; (2) mengganggu psychophysiology homeostatis seperti circadian rhythms, waktu tidur dan makan; (3) mengurangi kemampuan kerja, dan meningkatnya kesalahan dan kecelakaan; (4) menghambat hubungan sosial dan keluarga; dan (5) adanya faktor resiko pada saluran pencernaan, sistem syaraf, jantung dan pembuluh darah (Costa, 2003).

Dari banyaknya akibat negatif dari shift kerja, khususnya shift di malam hari, maka, berdasarkan studi-studi yang telah dilakukan, artikel ini akan merumuskan penyusunan shift kerja yang mempertimbangkan berbagai aspek kesehatan dan keselamatan kerja.

\section{KESELAMATAN DAN KESEHATAN KERJA, FATIQUE DAN SHIFT KERJA}

Kondisi keselamatan kerja yang optimal adalah sarana utama untuk mencegah kecelakaan kerja, cacat dan kematian akibat dari kecelakaan kerja. Keselamatan kerja bertalian dengan mesin, pesawat, alat kerja, bahan, dan proses pengolahannya, landasan tempat kerja dan lingkungannya serta caracara melakukan pekerjaan (Suma'mur, 1993). Sedangkan kesehatan kerja berhubungan dengan situasi dan lingkungan tempat kerja yang menyebabkan gangguan kesehatan.

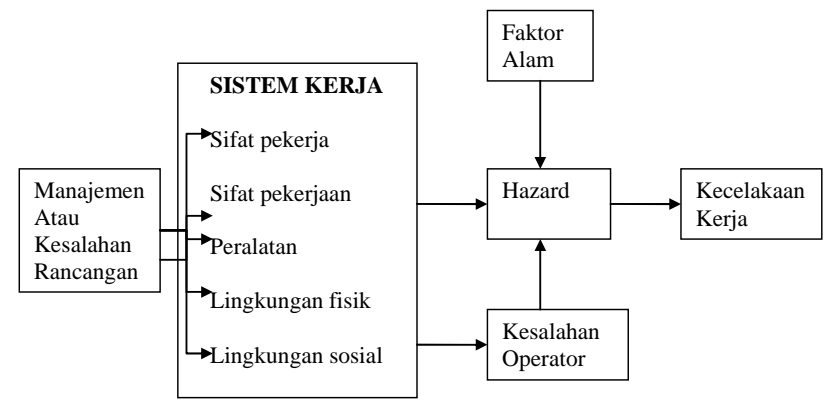

Gambar 1. Sistem Keselamatan Kerja

Beragam teori dan model telah dikembangkan untuk menjelaskan dan memperkirakan kejadian kecelakaan kerja. Umumnya pembahasan dari sebagian besar diantaranya berhubungan dengan analisis faktor penyebab kecelakaan. Salah satu diantaranya yang bersifat komprehensif adalah pendekatan sistem yang memandang kecelakaan kerja sebagai akibat interaksi dari berbagai komponen sistem. Komponen sistem meliputi pekerja yang menjalankan pekerjaan, pekerjaan itu sendiri dan peralatan kerja. Slappended dkk (Tayyari dan Smith, 1997) memformulasikan suatu model seperti terlihat dalam Gambar 1.

Faktor pekerja merupakan faktor yang sangat rentan terhadap kecelakaan kerja. Beberapa penelitian berhasil mengidentifikasi beberapa faktor manusia yang menyebabkan kecelakaan kerja yaitu umur, kemampuan, pengalaman, obat-obatan/alkohol, gender, stres, kelelahan (fatique), dan motivasi kerja.

Banyak perusahaan beroperasi lebih dari 8 jam per hari untuk memenuhi kebutuhan pasar dan karena keterbatasan sumber daya/fasilitas. Konsekuensinya, perusahaan harus melakukan shift kerja. Shift kerja adalah periode waktu dimana suatu kelompok pekerja dijadualkan bekerja pada tempat kerja tertentu. Disamping memiliki segi positif yaitu memaksimalkan sumberdaya yang ada, shift kerja akan memiliki resiko dan mempengaruhi pekerja pada:

\section{Aspek Fisiologis}

Circadian rhythms adalah proses-proses yang saling berhubungan yang dialami tubuh untuk menyesuaikan dengan perubahan waktu selama 24 jam (Tayyari dan Smith, 1997). Circadian rhythms menjadi dasar fisiologis dan psikologis pada siklus tidur dan bangun harian. Fungsi dan tahapan fisiologis dan psikologis memiliki suatu circadian rhythms yang tertentu selama 24 jam sehari, sehingga circadian rhythms seseorang akan terganggu jika terjadi perubahan jadwal kegiatan seperti perubahan shift kerja. Dengan terganggunya circadian rhythms pada tubuh pekerja akan terjadi dampak fisiologis pada pekerja seperti gangguan gastrointestinal, gangguan pola tidur dan gangguan kesehatan lain. Circadian rhythms berhubungan dengan suhu tubuh, tingkat metabolisme, detak jantung, tekanan darah, dan komposisi kimia tertentu pada tubuh. Circadian rhythms dipengaruhi oleh faktor lingkungan seperti terang, gelap, dan suhu lingkungan.

\section{Aspek Psikologis}

Stress akibat shift kerja akan menyebabkan kelelahan (fatique) yang dapat menyebabkan gangguan psikis pada pekerja, seperti ketidakpuasan dan iritasi. Tingkat kecelakaan dapat meningkat 
dengan meningkatnya stres, fatique, dan ketidakpuasan akibat shift kerja ini.

\section{Aspek Kinerja}

Dari beberapa penelitian baik di Amerika maupun Eropa, shift kerja memiliki pengaruh pada kinerja pekerja (Tayyari \&Smith, 1997). Kinerja pekerja, termasuk tingkat kesalahan, ketelitian dan tingkat kecelakaan, lebih baik pada waktu siang hari dari pada malam hari, sehingga dalam menentukan shift kerja harus diperhatikan kombinasi dari tipe pekerjaan, sistem shift dan tipe pekerja.

\section{Domestik dan sosial}

Shift kerja akan berpengaruh negatif terhadap hubungan keluarga seperti tingkat berkumpulnya anggota keluarga dan sering berakibat pada konflik keluarga. Secara sosial, shift kerja juga akan mempengaruhi sosialisasi pekerja karena interaksinya terhadap lingkungan menjadi terganggu.

Banyak penelitian model shift kerja dilakukan untuk mengurangi pengaruh negatif dari shift kerja tersebut. ILO membedakan 3 tipe shift kerja yaitu diskontinu, semikontinu dan kontinu. Shift juga dibagi menjadi 2 kelompok yaitu shift permanen/tetap dan dengan rotasi. Dua model shift konvensional yang umum dilakukan adalah:

- Continental Rota: 2-2-3 (2)/2-3-2(2)/3-22(3)

- Metropolitan Rota: 2-2-2(2)

Rotasi yang digunakan pada penulisan diatas menunjukkan: pagi-siang-malam (libur).

\section{FAKTOR DAN PENJADUALAN SHIFT KERJA}

Beberapa peneliti melakukan studi tentang shift kerja. Costa (2003) mengidentifikasi faktor-faktor utama yang mempengaruhi kesehatan pekerja dan toleransi shift kerja, seperti interaksi antar individu, kondisi sosial, dan organisasi kerja dalam menyusun suatu shift kerja.

Beberapa studi mengenai pengaruh shift kerja terhadap kinerja pekerja dan faktor-faktor yang mempengaruhinya juga telah dilakukan. Shift berpengaruh negatif terhadap kemampuan dan kinerja pekerja. Rough dkk
(2005) menyatakan bahwa shift kerja dalam waktu lama akan mengganggu circadian rhythms yang akan menimbulkan gangguan pada kinerja kognitf. Tomei dkk (2006) menyatakan bahwa ada kecenderungan meningkatnya kecemasan dan agresivitas pada akhir suatu shift. Aspek demografi seperti umur dan jenis kelamin banyak menyita perhatian peneliti terutama dalam pengaruhnya pada shift kerja. Harma dkk (2006) membuktikan bahwa walaupun shift berhubungan dengan tidur, mengantuk subyektif, kinerja dan kehidupan sosisl, tetapi umur hanya berpengaruh pada perubahan banyaknya tidur, rasa mengantuk subyektif dan kewaspadaan psikomotorik. Tidak ada hubungan langsung antara perbedaan umur dengan rasa mengantuk dan kinerja pada shift malam. Gustafsson (2002) menyatakan bahwa berkurangnya kualitas tidur pada pekerja wanita berpengaruh terhadap stres, mudah terinfeksi, ada perubahan mood dan somatic disstress. Oginska \& Pokorski(2006) menyatakan bahwa wanita membutuhkan waktu tidur lebih lama dari laki-laki. Wanita juga memiliki kecenderungan mudah mengalami kelelahan, perubahan mood dan masalah kognitif, juga diutarakan bahwa umur berbanding terbalik dengan lama waktu tidur.

Penentuan kecepatan rotasi shift kerja juga berpengaruh terhadap aspek fisik maupun mental pekerja (Lack \& Chamonux, 2004) karena adanya korelasi antara circadian rhythms dan ritme waktu tidur (Henning et al, 1998). Kostreva et. al (2002) mengkaji secara numeris circadian rhythms dalam penyusunan shift kerja dan mendukung hasil Czeisler (1992) yang menyatakan bahwa perubahan shift kerja harus perlahan, dan pola rotasi maju dengan waktu rotasi 2 minggu dengan waktu libur rata-rata 2 hari/minggu. Wu dan Wang (2002) mengidentifikasi waktu kerja yang optimal berdasarkan beban kerja fisik (dengan $\mathrm{VO}_{2}, \% \mathrm{VO}_{2 \max }$, dan $\mathrm{RVO}_{2}$ ). Shift kerja yang lama $(>10$ jam $)$ seharusnya dengan pengerjaan beban kerja yang lebih ringan dari intensitas shift 8jam. Batas beban kerja untuk shift kerja 4 jam dapat diberikan $\mathrm{VO}_{2 \max } 10 \%$ lebih dari yang disarankan untuk shift kerja 8 jam. Perbedaan inter-individual juga perlu dipertimbangkan dalam pengaturan shift kerja (Dongen, 2006). Berger dkk (2006) menyatakan bahwa tambahan durasi shift (extended-duration shift), yang didefinisikan bekerja lebih dari 24 jam terus menerus, akan 
meningkatkan tingkat kesalahan. Lima kali tambahan durasi shift per bulan akan meningkatkan kelelahan sampai 300\% dan berakibat fatal.

Waktu untuk mengembalian kebugaran dari kelelahan akibat kerja menjadi bagian yang penting dalam penyusunan shift kerja dan berhubungan dengan jadwal dan jam kerja. Jadual dan jam kerja akan berhubungan dengan kebutuhan pengembalian kebugaran berbeda antara pria dan wanita (Jensen et al, 2003; Jensen et al., 2002). Untuk mengurangi tingkat kesalahan, Berger dan Hobbs (2006) menyarankan untuk melakukan tidur siang pada pekerja shift malam, menghilangkan kerja lembur hingga lebih 12 jam dan mengerjakan tugas sebelum jam 4 pagi untuk shif malam. Pada waktu akhir shift malam setelah jam 4 pagi, terjadi perubahan tingkat cortisol, suhu badan dan tingkat melatonin yang akan berpengaruh pada kinerja pekerja. Tidur sebentar dalam tugas shift malam berdampak positif untuk mengurangi kelelahan tanpa mengurangi kinerja (Arora dkk, 2006). Waktu istirahat juga dapat mengurangi musculoskeletal discomfort (MSD), gangguan mata, mood dan kinerja pekerja (Galinsky dkk, 2000).

\section{KESIMPULAN}

1. Terdapat dua golongan penyebab kecelakaan yaitu tindakan/perbuatan manusia dan keadaan lingkungan. Faktor manusia menempati posisi yang sangat penting terhadap terjadinya kecelakaan kerja yaitu antara $80-85 \%$ dan kelelahan kerja memberi kontribusi $50 \%$ terhadap terjadinya kecelakaan kerja.

2. Shift kerja berpengaruh (1) negative terhadap kesehatan fisik, mental dan sosial; (2) mengganggu psychophysiology homeostatis seperti circadian rhythms, waktu tidur dan makan; (3) mengurangi kemampuan kerja, dan meningkatnya kesalahan dan kecelakaan; (4) menghambat hubungan sosial dan keluarga; dan (5) adanya faktor resiko pada saluran pencernaan, sistem syaraf, jantung dan pembuluh darah

3. Beberapa poin yang perlu diperhatikan dalam penyusunan shift kerja antara lain: a. Penggantian shift kerja sebaiknya dengan pola rotasi maju dengan waktu rotasi kurang dari 2 minggu dan dengan waktu libur rata-rata 2 hari/minggu

b. Lama shift kerja sebaiknya tidak lebih dari 8 jam, jika lebih dari jam tersebut beban kerja sebaiknya dikurangi

c. Pada pekerja dengan shift malam dianjurkan ada waktu tidur siang sebelumnya dan bila melaksanakan pekerjaan dengan pertimbangan khusus sebaiknya dilaksanakan sebelum jam 4 pagi agar kesalahan dapat dikurangi

d. Aspek demografis seperti jenis kelamin dan umur perlu diperhatikan dalam penyusunan shift kerja

\section{DAFTAR PUSTAKA}

-----, (2007). Fatal Work Injuries down, Industrial Engineer.

Arora, V., Dunphy, C., Chang, V.Y, Ahmad, F., Humphrey, H.J., Meltzer, D. (2006). The Effect on-Duty Naping on Intern Sleep Time Fatique, Annals of internal Medicine, 144(11), 793-802.

Bennefond, A., Harman, M., Hakola, T., Sallinen, M., Kandolin, I., dan Virkkala, J. (2006). Interaction of age with shift-related sleep-wakefulness, sleepiness, performance and social life, experimental aging research, 32, 185-208.

Berger, A. M., dan Hobbs, B. (2006a). Impact of shift work on health and safety on nurses and patients, Clinical Journal of Ocology Nursing, 10(4), 465-480.

Berger, L. K., Ayas, N., Cade, B.E., Cronin, J. W., Rosner, B., Spiizer, F., E., Czeisler, A. (2006). Impact of extended-duration shifts on medical errors, adverse events and attentional failures, Plos Medicine, 3(12), e487.

Costa, G. (2003) Factors Influencing health of workers and tolerance to shift work, Theory Issues in Ergonomic Science, 4, 263-288.

Czeisler, C. A., Moore-Ede, M. C. And Coleman, R. C. 1982, Rotating Shift Work Schedules That Disrupt Sleep Are 
Improved By Applying Circadian Principles, Science, 217, 460 \pm 463 .

Dongen, H. P. (2006). Shift Work and interindividual difference in sleep and sleepiness, Chronobiology International, 23(6), 1139-1147.

Galinsky, T., Swanson, N. G., Sauter, S. L., Hurrell, J., Schleifer, L. M. (2000). A field study of supplementary rest breaks for data-entry operators, Ergonomics, 43(5), 622-638.

Gustafsson, U. M. (2002). Sleep Quality and response to insufficient sleep in women on different work shifts, journal of clinical nursing, 11, 280-288.

Harrison y. \& Horne J. (2000). The impact of sleep depriviation on decision making: a review. Journal of experimental Psychology: applied, 6 (3), 236-358.

Henning, J., Kieferdorf, P., Moritz, C., Huwe, S. And Netter, P. (1998). Changes In Cortisol Secretion During Shiftwork: Implications For Tolerance To Shiftwork? Ergonomics, 41, 610-621.

ILO. (2003). Encyclopedia of Occupational Health and Safety, Geneva.

Jansen, N. W. H., Kant, I. J. And Van Den Brandt, P. A. (2002). Need for recovery in the working population: description and associations with fatigue and psychological distress, International Journal of Behavioral Medicine, 9, 322-340.

Jansen, N. W. H., Kant, I. J. Van Amelsvoort, L., Nijhuis, F. and Van Den Brandt, P. A. (2003). Need for recovery from work: evaluating short term effect of working hours, patterns and schedule, Ergonomics, 46(7), 664-680.

Kostreva, M., McNelis, E., Clemens, E. (2002). Using a Circadian rhythms model to evaluate shift schedule, Ergonomics, 45(11), 739-763.

Lack, G. and Chamonux, A. (2004). Biological and Psychological response to two rapid shiftwork schedules, Ergonomics, 47(12), 1339-1349.

Oginska H. dan Pokorski, J. (2006). Fatigue and mood correlates of sleep lengthin three age-social groups: school children, students, and employees, Chronobiology International, 23(6): 1317-1328.

Palmer, B., Gentner, F., Schopper, A, \& Sottile, A. (1996). Review and Analysis: Scientific review of air mobility command and crew rest policy and fatique issues, fatique Issue, 1-2.

Rouch, I., Wild, P., Ansiau, D., dan Marquie, J. C. (2005). Shift experience, age and cognitive performance, Ergonomics, 48(10), 1282-1293.

Setyawati, L. M. (2007). Promosi Kesehatan dan Keselamatan Kerja, Pelatihan Para Medis Seluruh Jawa Tengah, RSU Soeradji Klaten.

Sharpe, J. (2007). Shift work and long hours: risky business, Rock Product. January 2007, 11.

Silalahi, B. N.B.S., dan Silallahi, R. B. (1991). Manajemen Keselamatan dan Kesehatan Kerja, PT Pustaka Binaman Pressindo, Jakarta.

Suardi R. (2005). Sistem manajemen keselamatan dan kesehatan kerja, Penerbit PPM, Jakarta.

Suma'mur P. K. (1993). Keselamatan Kerja dan Pencegahan Kecelakaan, Haji Masagung, Jakarta.

Tayyari F. dan Smith, J. L. (1997). Occupational Ergonomics: Principles and Applications, Chaman \& Hall, London.

Tomei, G., Cherubini, E., Ciarrocca, M., Biondi, M., Rosati, M., Tarsitani, L., Capozzella, A., Monti, C., dan Tomei F. (2006). Short communication: Assessment of subjective stress in the municipal police force at the start and at the end of the shift, Stress and Health, 22, 239-247.

Wicken, C. D., Lee, J. D., Liu, Y., Becker, S. E. G., (2004). An Introduction To Human Factors Engineering, Prentice Hall, New Jersey.

Wu, H.C. dan Wang, M. J. (2002). Relationship between maximum acceptable work time and physical workload, Ergonomics, 45(4), 280-289. 